\title{
UHI ESTIMATION BASED ON ASTER AND MODIS SATELLITE IMAGERY: FIRST RESULTS ON STRASBOURG CITY, FRANCE
}

\author{
S. Del Pozo ${ }^{1, *}$, T. Landes ${ }^{2}$, F. Nerry ${ }^{3}$, P. Kastendeuch ${ }^{3}$, G. Najjar ${ }^{3}$, N. Philipps ${ }^{3}$, S. Lagüela ${ }^{1}$ \\ ${ }^{1}$ Department of Cartographic and Land Engineering, University of Salamanca, Ávila, Spain - (s.p.aguilera, sulaguela)@ usal.es \\ 2 ICube Laboratory, Photogrammetry and Geomatics Group, National Institute of Applied Sciences (INSA), \\ Strasbourg, France- tania.landes@insa-strasbourg.fr \\ ${ }^{3}$ ICube Laboratory, UMR 7357 CNRS-University of Strasbourg, Illkirch, France - (georges.najjar, kasten, f.nerry)@unistra.fr, \\ nathaliaphilipps@gmail.com
}

Commission III, WG III/8

KEY WORDS: Urban Heat Island, Land Surface Temperature, Satellite Remote Sensing, Weather Stations, ASTER, MODIS

\begin{abstract}
:
The increase in urbanization of cities coupled with some effects of climate change is leading to the emergence of urban microclimates. The rising temperatures in cities create the phenomenon known as Urban Heat Island (UHI). This is a difference between the temperature of urban and rural areas that intensifies more during the night and varies according to the season of the year. This paper focuses on the estimation of the UHI and its variations in and around the city of Strasbourg. To this end, thermal remote sensing data from different satellite has been used to isolate and analyse this phenomenon, specifically, Land Surface Temperatures (LSTs) provided by ASTER and MODIS. The LST provided by these sensors has been compared to air temperatures of the last 15 years from meteorological stations distributed throughout the city that have served as ground truth. Forty-seven meteorological stations spread throughout the area of interest provided measurements of air humidity and temperature. This valuable data base has allowed the assessment of the correlations between LST from satellite and ground truth air temperature. Based on satellite data resampled at different spatial units, this work led to the creation of the first UHI map of Strasbourg.
\end{abstract}

\section{INTRODUCTION}

\subsection{Causes and effects of UHI}

As our civilization is facing more natural crisis, global warming becomes increasingly evident (Pereira et al., 2020). Wildfires in Australia are just one dreadful event among others (Arriagada et al., 2020), such as droughts in China and floods in Fiji Islands (Keyimu et al., 2020; Merschroth et al., 2020).The last report of the GIEC (Intergovernmental Panel on Climate Change, 2018) is greatly alarming. It depicts what the consequences of a generalized temperature increase of $1.5^{\circ} \mathrm{C}$ would be. Such an increase would have an impact on the regional climate with greater frequency of extreme temperatures. For example, at mid-latitudes, during the warm season, increases of up to $3^{\circ} \mathrm{C}$ above the usual temperature could be expected.

Urbanization is constantly on the rise (Aboulnaga et al., 2019). In 2018, 55\% of the world's population lived in urban settlements. In 10 years, urban population is expected to reach $60 \%$. Urban areas consume $78 \%$ of the global energy while representing only $2 \%$ of the Earth's surface and are responsible for $60 \%$ of global $\mathrm{CO}_{2}$ emissions. This increase in urbanization has a direct effect on the increase in urban temperature at ground and air level (Paranunzio et al., 2019). This phenomenon is known as Urban Heat Island (UHI), which is defined as an urban microclimate where ground and air temperatures are higher than those recorded in rural areas (Oke, 1982).

\subsection{Land Surface Temperature}

Howard (Howard, 1833) was the first scientific to highlight the connection between cities and the emergence of microclimates and, therefore, he evidenced the UHI phenomenon. The UHIs are particularly notable during the night and even more when certain weather conditions are met: low or non-existent wind, clear skies and high global radiation during the day. In this regard, the study and analysis of the variation of LST on a suitable scale can demonstrate not only the manifestation of this phenomenon in urban areas but also the implication of the different land covers in its exacerbation or mitigation. In addition, this parameter is closely linked to other environmental variables for studying the impact of climate change such as land uses, presence of greenhouse gases or percentage of vegetation cover among others (Sánchez-Aparicio et al., 2020).

\section{RELATED WORK}

Many papers have been written over the past few years on this subject, showing the great scientific interest of studying and minimizing this phenomenon (Martilli et al., 2020).Knowing how to regulate and reduce such a thermal behaviour as well as understanding the factors involved is of crucial importance for urban planners and mayors.

Earth observation data from satellite systems is useful for monitoring this phenomenon with high temporal and spatial variability. Indeed, satellite sensors can cover large areas which is suitable for studying the UHI effect on a city and its surroundings. Another advantage is their high temporal resolution, and that many of them are open data. The most used land observation data for UHI studies are those from Landsat, MODIS, ASTER and AVHRR satellites. Since UHIs are particularly notable during the night, this paper focuses on MODIS and ASTER due to their nocturnal thermal data acquisitions. Specifically, LST products from those satellites

\footnotetext{
* Corresponding author
} 
have been used to study its relationship with air temperature at ground level.

The paper is divided into 5 sections. After related works, in Section 3, the study area as well as the data used for the UHI analysis are described. Then, in Section 4, all the correlations performed between LST and air temperature from both ASTER and MODIS as well as the first UHI map of Strasbourg are shown and discussed. Finally, Section 5 outlines the main conclusions obtained and future work.

\section{CASE STUDY AND DATASETS}

Our experiment benefits from a long-term fieldwork experiment to measure and monitor the urban climate of the city of Strasbourg, particularly focusing on the role of vegetation in micro-climatic conditions (Najjar et al., 2015).

\subsection{Study area}

The study is focused on the city of Strasbourg and its surroundings (Figure 1). Strasbourg is in the plain of Alsace and is separated from Germany by the Rhine river. The Eurometropolitan area of Strasbourg (Figure 2a) covers 339,64 $\mathrm{km}^{2}$ and has 494.089 inhabitants according to the 2017 records. This represents a population density of 1.500 inhabitants per $\mathrm{km}^{2}$, proving to be the most populated area in Alsace.

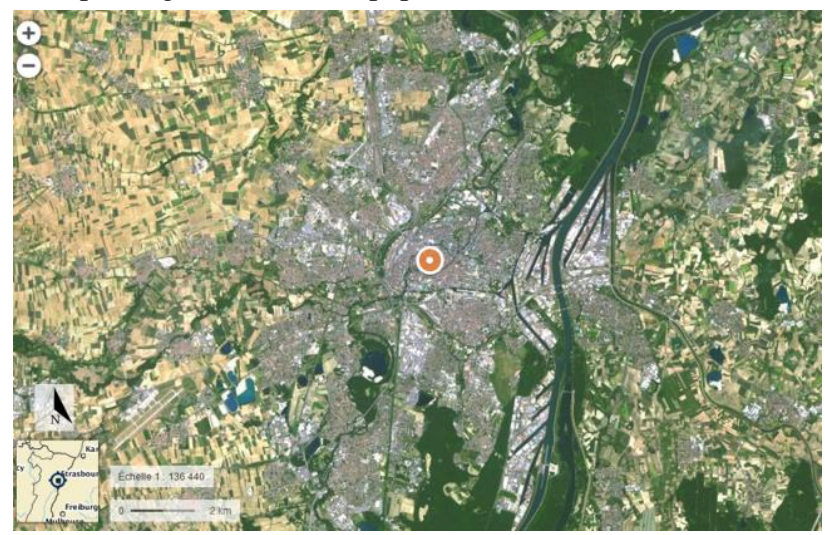

Figure 1. Location of Strasbourg, Alsace, France. Source: French national geoportail.

Strasbourg is relatively flat, and it is located on the largest water reserve in Europe. The urban typology is diverse. The historical part of the city (Petite France) consists on narrow streets with relatively close buildings. However, in the modern district there are large, straight, and wide avenues with lower building density. On the other hand, there is the campus district made up of high-rise buildings as well as the two industrial zones of the city to the east and southwest of Strasbourg. Nevertheless, it has many green spaces and large parks scattered throughout the city, representing around 234 ha.

Strasbourg is characterized by semi-continental climate, that is, cold winters and hot summers (Figure 2c) with large temperature variations between seasons, from $-10^{\circ} \mathrm{C}$ in winter to $35^{\circ} \mathrm{C}$ in summer. In general, it has a little exposure to wind, but foggy days are frequent.

Due to the high urbanisation level and population density, Strasbourg is subject to UHI effects and extreme temperature increases as those occurred in the summers of 2003, 2015 and 2019.

\subsection{Satellite Data}

The most used satellites for studying UHIs are Landsat, MODIS, ASTER and AVHRR. The first choice to map UHIs in Strasbourg was the use of MODIS due to its great temporal resolution (Table 1). However, it was quickly decided to complement this data source with ASTER due to its higher spatial resolution and the advantage that both sensors are onboard the same spacecraft (Terra), so that they monitor the same point on Earth with a time lag of 3 min difference. Indeed, by combining the advantages of both satellites, it will be possible to obtain more reliable results as more data is available to be correlated.

Since the effect of the UHI is more evident during the night, Landsat- 8 was discarded, because although it offers thermal data with a spatial resolution of $30 \mathrm{~m}$, it does not offer thermal information at night.

Specifically, the satellite products used to derive surface temperature remotely acquired and air temperature at ground level were AST-08 and MOD11-L2 from ASTER and MODIS, respectively. Both correspond to Level 2 processed products from NASA with different characteristics as Table 1 shows. On the other hand, for mapping the UHI effect, MOD11A1 instead of MOD11-L2 was used because of lower lack of data due to the presence of clouds as a product that averages TLS values available for the night.

\begin{tabular}{|c|c|c|}
\hline Satellite & ASTER & MODIS \\
\hline Product & AST-08 & MOD11-L2/MOD11A1 \\
\hline Swath & $60 \mathrm{~km} \times 60 \mathrm{~km}$ & $2300 \mathrm{~km} \times 2000 \mathrm{~km}$ \\
\hline Temporal res. & On demand & $<$ daily \\
\hline Spatial res. & $90 \mathrm{~m}$ & $1 \mathrm{~km}$ \\
\hline Radiometric res. & 12 bits & 16 bits \\
\hline Algorithm & TES & Split Window \\
\hline TIR bands & B10: $8.125-8.475$ & B31: $10.780-11.280$ \\
\hline & B11: $8.475-8.825$ & B32: $11.770-12.270$ \\
\hline & B12: $8.925-9.275$ & \\
\hline & B13: $10.25-10.95$ & \\
\hline & B14: $10.95-11.65$ & \\
\hline Units & K with a SF*: 0.1 & K with a SF*: 0.02 \\
\hline Abs. accuracy** & $1-4 \mathrm{~K}$ & $0-3 \mathrm{~K}$ \\
\hline $\begin{array}{r}\text { Time crossing } \\
\text { Strasbourg }\end{array}$ & $10: 33 / 21: 18$ & $10: 30 / 21: 15$ \\
\hline Delivery format & Geotiff & Hdf \\
\hline Spacecraft & Terra & Terra \\
\hline
\end{tabular}

Table 1. Features of satellite data.*Scale Factor, **Depending the emissivity.

3.2.1 AST-08: LST product offered by ASTER that corresponds with Surface Kinetic Temperature for land areas at 90-m resolution for both day and night. The product is determined by the TES algorithm (Guillespie et al., 1998) based on the emissivity from the AST-05 product and from the combination of their five TIR bands. The main limitations of AST-08 are its temporal resolution (only offers TLS images on demand), its cloud mask unavailability and the requirement of using two consecutive AST-08 images with a 9-min time lag for covering Strasbourg.

3.2.2 MOD11-L2: LST product offered by MODIS-Terra generated by the Split-Window algorithm (Wan and Dozier, 1996) and using only two TIR bands, band 31 and 32. It offers LST either during the day or night at $1-\mathrm{km}$ spatial resolution with the advantage that all pixels covered by clouds are previously masked and therefore, LST data extracted is errorfree. 
3.2.3 MOD11A1: This product provides daily nighttime/daytime LST at $1-\mathrm{km}$ spatial resolution in a $1200 \mathrm{~km}$ $\mathrm{x} 1200 \mathrm{~km}$ grid corresponding with the average of the LST values from MOD11-L2 for the night or the day to the same Earth location on the sinusoidal projection. This product contains lower empty pixels due to the presence of clouds and for that reason it was chosen to map the UHI instead of the MOD11-L2 product.

\subsection{Air Temperature at Ground Level}
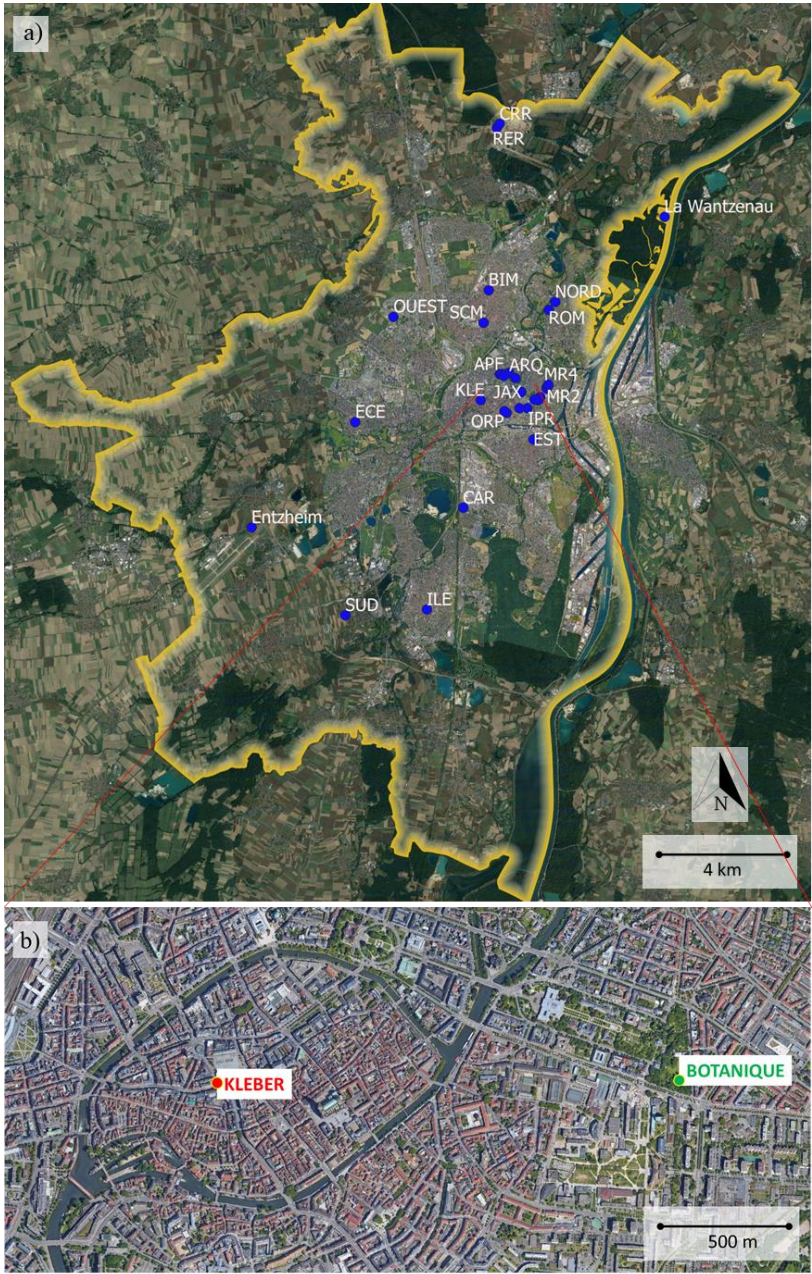

c) SPRING
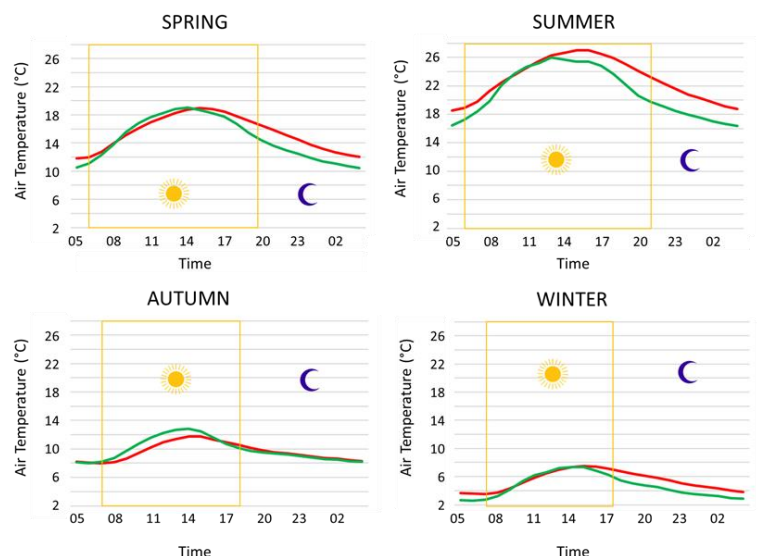

- KLeBer - Botanique

Figure 2. a) Location of the meteorological stations (blue points) in the Eurometropolitan area of Strasbourg (yellow boundary), b) Kleber and Botanique stations and c) the annual variations of air temperatures in such stations.
For analysing temperature changes between urban and rural areas, different locations distributed throughout the study area that match different surface coverages should be analysed. In this study, at each chosen location, a meteorological station recorded hourly information on air temperature at a height of 2 $\mathrm{m}$ with an accuracy of $\pm 0.5^{\circ} \mathrm{C}$.

As shown in Figure $2 \mathrm{a}$, a total of 47 meteorological stations distributed in the city of Strasbourg were recording the aforementioned climatic data. Some of the meteorological stations belonged to Météo France and others to the University of Strasbourg. The exact location per meteorological station was known (Figure 2a) and, therefore, the urban characteristics of the land cover to which they belong were also known. The measurements recorded regularly since 2012 in each location has constituted a valuable database for carrying out climate studies.

Regarding the particular behaviour of temperatures depending on the land cover, Figure $2 \mathrm{c}$ reveals this variation for two meteorological stations located in the centre of Strasbourg. Specifically, the annual thermal variability between the Botanique and Kleber stations at just $1.75 \mathrm{~km}$ distance from one to another was graphed (Figure 2b). The Botanique station is located in an urban park and the Kleber station in an urban square. Although during the day the temperature registered at the Botanique station is comparable to that of the Kleber station, even exceeding at some times of the day by up to 1 degree (in Autumn), is at night when temperature between them is up to 4 degrees, accentuating this nocturnal behaviour more in Summer. This states the effect that an urban cover has in the air temperature.

\section{METHODS AND RESULTS}

The following analyses were performed in order to: (i) assess correlations between the LST at satellite level and air temperature measured at the same time at ground level and (ii) analyse the relationship between LST data from ASTER and MODIS:

Correlations between AST-08 (both pixel and resample-based) and air temperature at ground level.

Correlations between MOD11-L2 and air temperature at ground level.

Correlations between AST-08 and MOD11-L2.

In addition to the correlations, an uncertainty assessment subsection has been enclosed in order to discuss about the expected absolute error derived from using AST-08 and MOD11-L2 products to analyse air temperatures.

Finally, a first map of the UHI effect in the Eurometropolitan area of Strasbourg has been obtained and analysed based on the MOD11A1 satellite product.

\subsection{Pixel-based AST-08 vs. Air Temperature}

The first analysis considered was the comparison between air temperatures measured at ground level with the LST from ASTER at a 90-m pixel size for each of the meteorological stations with available data. Regarding LST at satellite level, all AST-08 products available for the study area between 2012 and 2019 for both day and night were used. Only 20 products were available given the on-demand purchasing limitations of this product.

Before comparing both data sources, and since meteorological stations recorded temperatures hourly, temperatures had to be interpolated to get values at 10:33 and 21:18 (exact time at which ASTER crosses Strasbourg). Specifically, a seconddegree polynomial interpolation was chosen for getting these values in view of the good fit to thermal behaviour (Figure 3 ). 


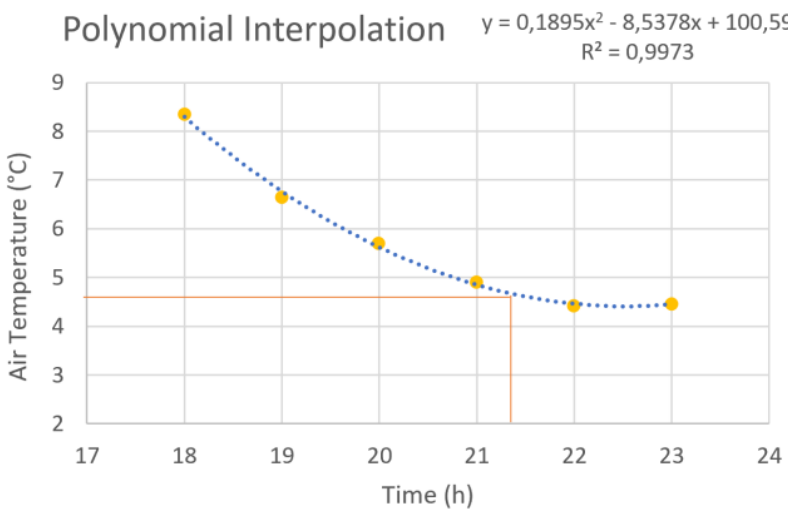

Figure 3. Example of second-degree polynomial interpolation between hourly temperature data registered by the meteorological stations in order to get the temperature at 21:18.
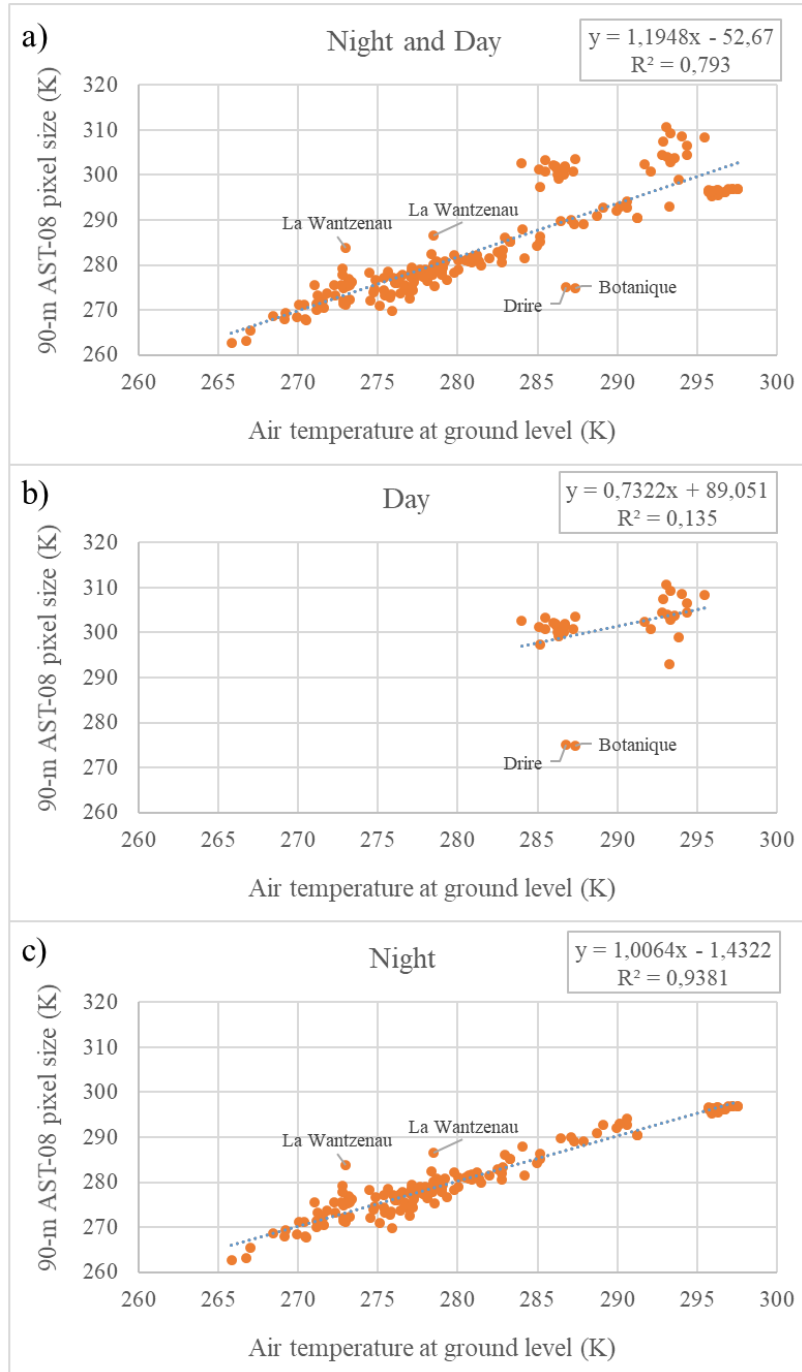

Figure 4. a) Correlation between pixel-based AST-08 and air temperatures at ground level for all satellite products available both day and night between 2012-2019, b) same correlations for daily data, and c) same correlations for nightly data.

As shown in Figure 4a, the existence of a linear correlation between pixel-based AST-08 and air temperature at ground level is deduced based on data for the 20 dates analysed between 2012-2019. Deepening more, this correlation improves greatly when only nightly data is considered (Figure 4c) being proving that there is no linear correlation between the daytime LST and air temperature $\left(\mathrm{R}^{2}=0.1350\right.$, Figure $\left.4 \mathrm{~b}\right)$. For that reason, the subsequent analyses only contemplate nightly data. Finally, considering only the nocturnal data (Figure $4 c$ ), an $\mathrm{R}^{2}$ fitting coefficient of 0.9381 was obtained. This result confirms the linear relationship between LST at satellite level and air temperature at ground level at night.

\subsection{Resample-based AST-08 vs. Air Temperature}

Since the variations of air temperature might be different depending on the extension of the area considered around a meteorological station, the second analysis consisted of comparing the air temperature measured at ground level with the LST from AST-08 previously resampled at two different pixel sizes: from $90 \mathrm{~m}$ to $400 \mathrm{~m}$ first, and from $90 \mathrm{~m}$ to $1 \mathrm{~km}$ later. Only night data was used in this case (Figure 5).
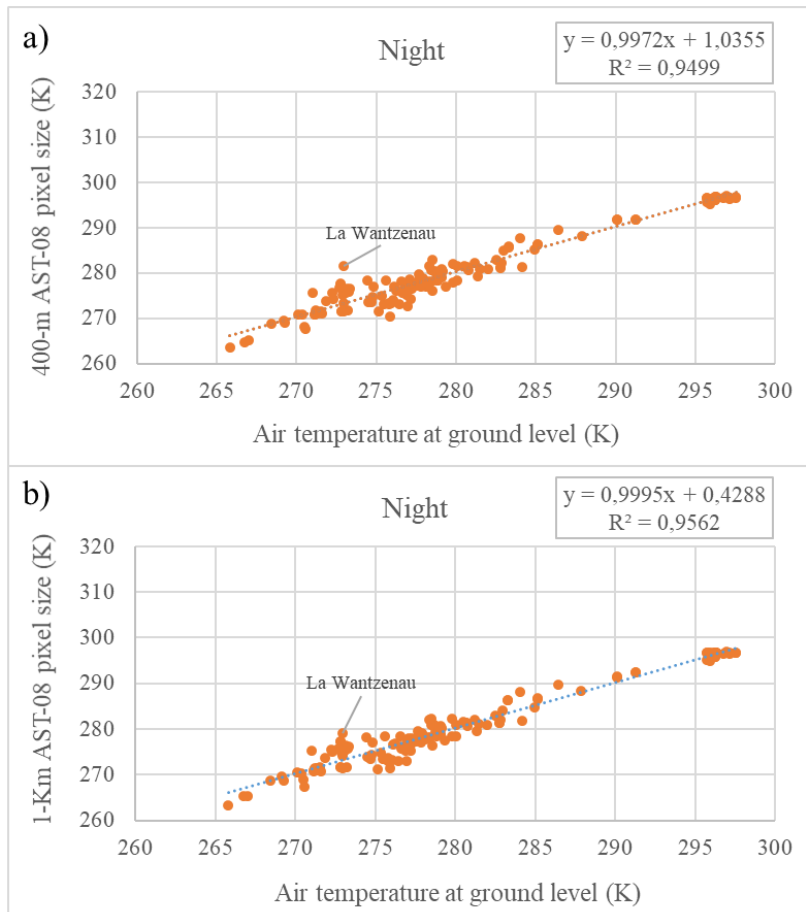

Figure 5. a) Correlation between the resample-based AST-08 product at a $400-\mathrm{m}$ pixel size and air temperatures at ground level for all satellite products available at night and b) same correlations with AST-08 at a 1-km pixel size.

The resampling was performed by averaging the LST values corresponding to the pixels that fell within the new pixel size. Thus, for the 400-m AST-08 pixel size, each pixel value was the average of LST values from a grid of approximately 25 pixels (5x5). For its part, the average of LST values from a grid of 121 pixels $(11 \mathrm{x} 11)$ was the final LST value of each $1-\mathrm{km}$ AST-08 pixel. With respect to the correlation between these products and air temperatures, a slight improvement of the coefficient $\mathrm{R}^{2}$ was observed as the buffer increases in size. Specifically, the $\mathrm{R}^{2}$ obtained was 0.9499 and 0.9562 , respectively.

\subsection{Pixel-based MOD11-L2 vs. Air Temperature}

The third analysis considered the nocturnal LST values from MODIS at each original pixel size $(1 \mathrm{~km})$ for the same set of dates for which nighttime AST-08 data was available and air temperatures measured at ground level at each meteorological stations with available data (Figure 6). 
Before comparing both data sources, temperatures from meteorological stations were previously interpolated according to a second-degree polynomial to obtain values at 21:15 (exact nigh time at which MODIS crosses Strasbourg).

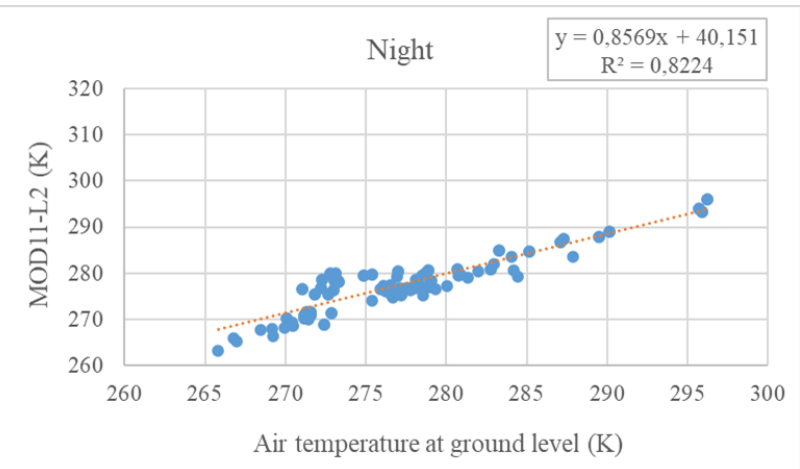

Figure 6. Correlation between pixel-based MOD11-L2 and air temperatures at ground level for all MODIS satellite products available for the same dates for which AST-08 products were available.

This analysis proves what was already revealed in the previous section: there is a linear relationship between LST acquired by satellite and air temperature measured at ground level even when a $1 \mathrm{~km}$ pixel size satellite product is used. In this case, and although it is not considered of great relevance, the adjustment worsens slightly compared to when using LST from ASTER (for any of the three resolutions analysed). Specifically, an $\mathrm{R}^{2}$ fitting coefficient of 0.8224 was obtained when comparing MOD11-L2 with air temperature.

\subsection{Resample-based AST-08 vs. Pixel-based MOD11-L2}

Finally, a last comparison was made in order to show similarities/differences when calculating LST based on different algorithms and by using different TIR bands. Thus, LST products offered by ASTER and MODIS for the same pixel size $(1 \mathrm{~km})$ were here compared. As shown in Figure 7, a good fit was derived between both satellite products reaching an $\mathrm{R}^{2}$ fitting coefficient of 0.9140 . Although two outliers are observed from La Wantzenau station, the good $\mathrm{R}^{2}$ coefficient shows that the different algorithms and methodologies used by ASTER and MODIS to derivate LST data (TES and Split Window, respectively) as well as the different thermal bands used in both cases (in number and wavelength) are compatible.

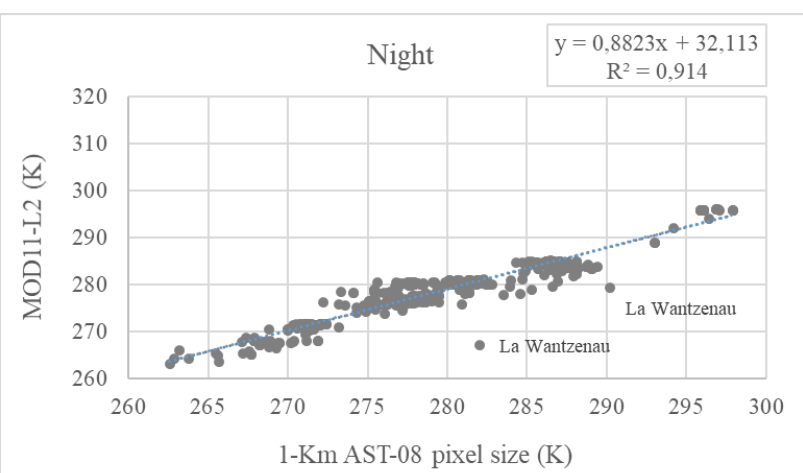

Figure 7. Correlation between $1 \mathrm{~km}$ AST-08 pixel size and MOD11-L2 original pixel size.

\subsection{Discussion about LST vs air temperature}

Based on the results, in which an evident linear relationship between nightly LST and air temperature is obtained, it can be established that both ASTER and MODIS data sources could be used to derive air temperatures. However, this section goes one step further dealing with expected error estimation if either of these two satellite data sources is used to derive air temperatures. In this sense, although surface temperature and air temperature are two different parameters, we wanted to compare them in order to estimate the absolute error obtained when deriving air temperature with them. The absolute error was computed as the resulting difference between the LST from each satellite product and the air temperature at ground level. Figure 8 shows the absolute error in terms of its maximum, mean and standard deviation for each satellite product.

As a summary, and for AST-08 products, decreasing absolute errors have been obtained as the pixel size increased with the resampling process. On the other hand, the maximum absolute error derived from the use of MOD11-L2 is close to that obtained from the use of $1 \mathrm{~km}$ AST-08 pixel size product. On the other hand, the mean value of absolute errors when using MOD11-L2 exceeds the three corresponding mean values of absolute error when using each of the AST-08 resolutions. However, the mean values for all products are within the expected thresholds of accuracy that NASA assures for such data. Finally, the locations for which the greatest absolute error were obtained were: La Wantzenau, Botanique and Stattmatten. As shown in Figure 9, La Wantzenau station is in an artificial environment surrounded by a large vegetated area and the Rhine river that passes close to it. This could also explain the outliers in Figure 7.

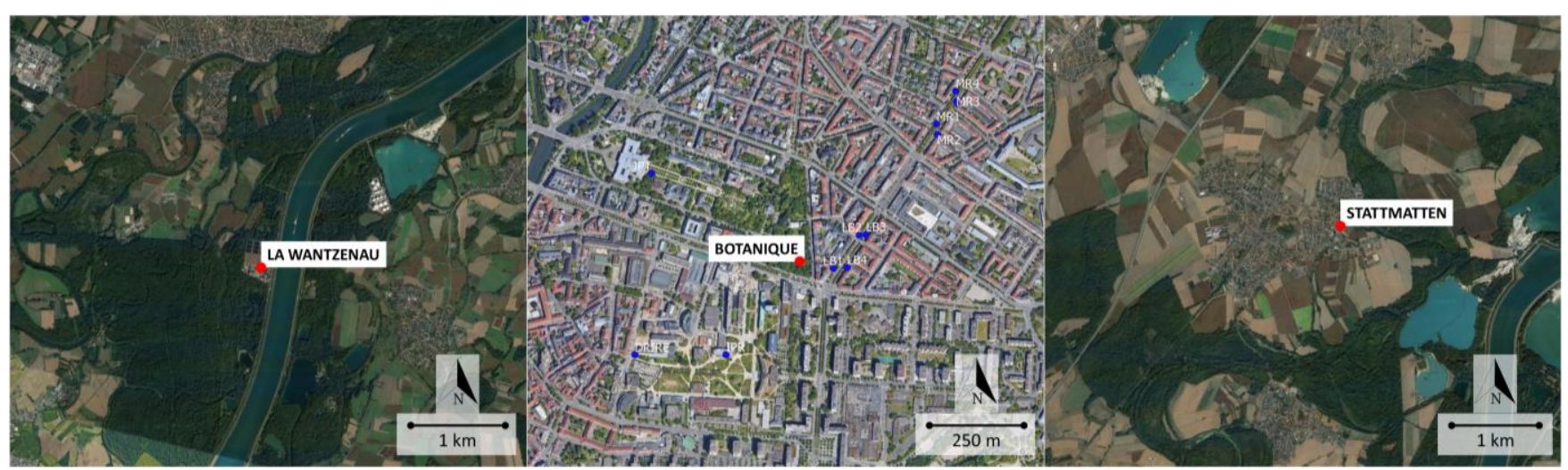

Figure 9. Locations for which maximum absolute error between LST and air temperature were obtained. Source: GoogleMaps. 


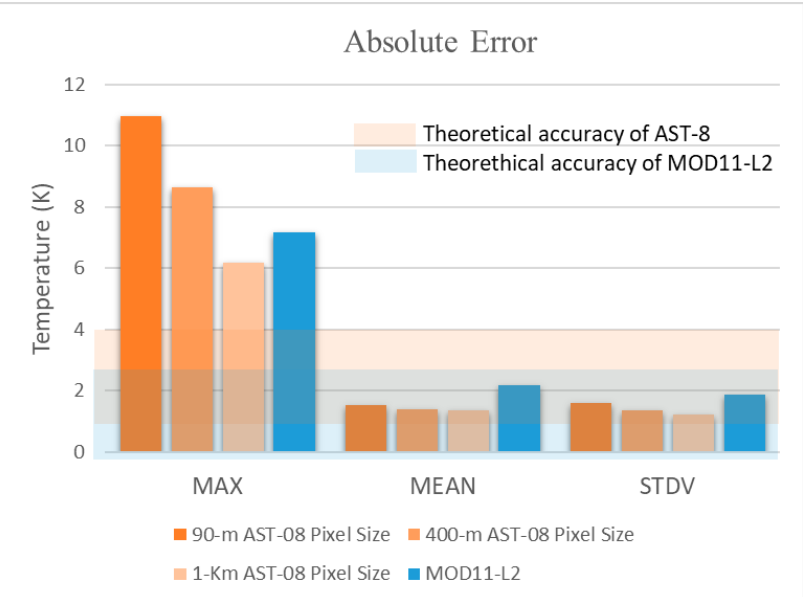

Figure 8. Maximum, mean and standard deviation of the absolute errors obtained when using AST-08 product at the three spatial resolutions analysed (in orange) and when using MOD11-L2 (in blue).

The explanation of the higher errors could be given by the basis of the influence that humidity causes on temperature. In this case, the evaporation arising in the Rhine river added to the evapotranspiration arising in the forest mass that surrounds $\mathrm{La}$ Wantzenau station could explain this exception.

For its part, the Botanique is a natural park embedded in the city that may be influenced by such artificial land cover of its surroundings. Finally, the Stattmaten station is in a small town whose surroundings are very similar to those of La Wantzenau. A deeper study in this regard should be done to find out the compelling reasons why the thermal behaviour at these places is different.

\subsection{UHI Mapping}

Based on the linear relationship between LST and air temperature, especially at night, nightly LST from ASTER or MODIS could be used to derive air temperature and to monitor the UHI phenomenon. In this regard, and in order to check and visualize the existence or non-existence of microclimate behaviour in the city of Strasbourg, a first UHI map of the city was generated based on LST data from MOD11A1 and for March 26, 2012 at night (Figure 10).

In view of these first results, we can say that Strasbourg has a microclimate thermal behaviour which is evidenced with a temperature increase of up to $6 \mathrm{~K}$ when comparing the city centre and the immediate rural areas that are only $7.5 \mathrm{~km}$ away. Regarding the morphology and spatial distribution of the UHI, we observe that although it follows a concentric and radial behaviour, it flattens slightly horizontally. This effect can be explained by the thermal influence applied by the Rhine river that crosses the city from north to south from the eastern side. In addition, this could be explained due to the concurrence of the two industrial areas of the city at that zone.

Finally, through this preliminary map, the warmest area of Strasburg is shown which corresponds exactly to the very dense city centre (Petite France) where narrow streets with relatively close buildings takes place.

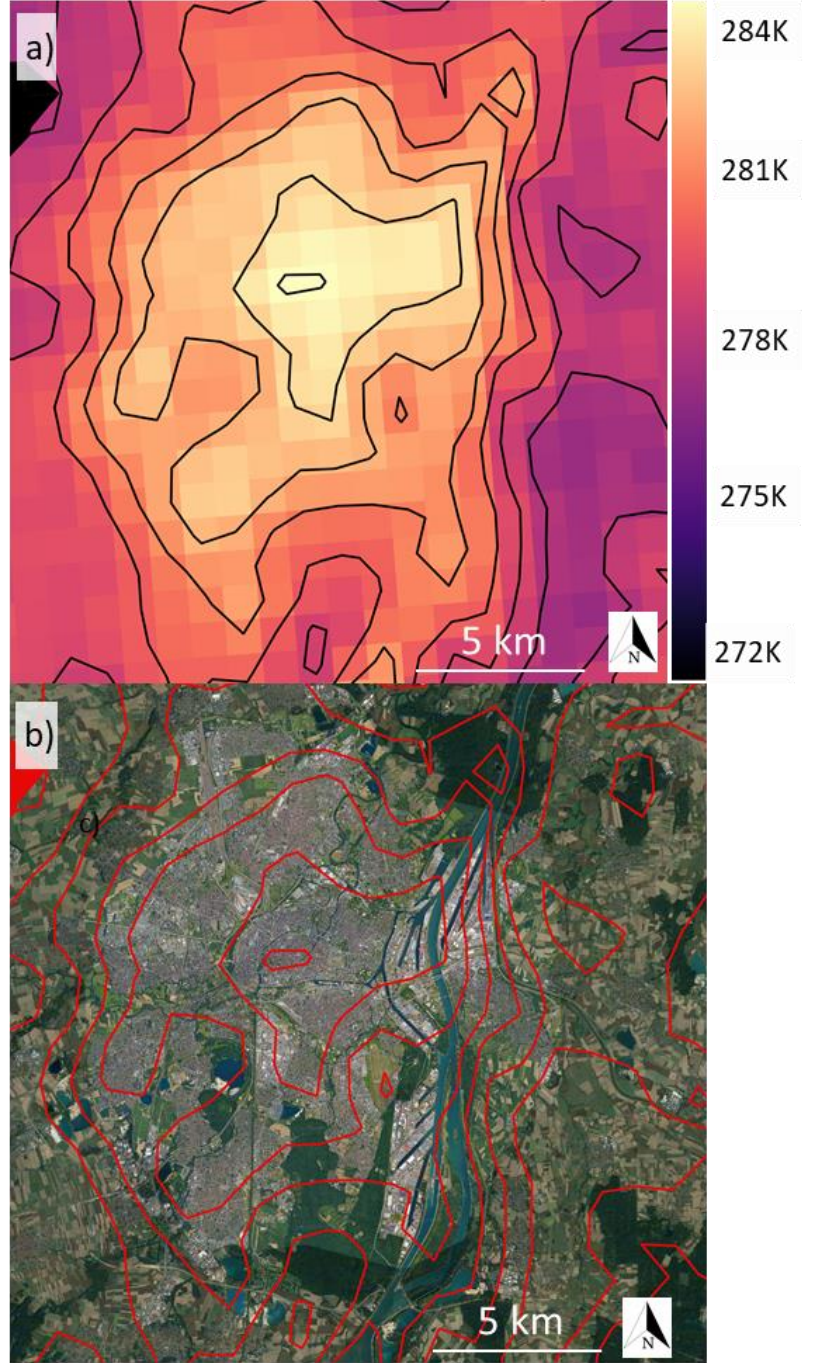

Figure 10. a) Spring UHI map of Strasbourg obtained from MOD11A1 LST product at night and b) the isotherms derived every $1 \mathrm{~K}$ superimposed on an aerial image of the city from GoogleMaps.

\section{CONCLUSION}

This initial study has proved that: a) there is a direct correlation between LST and air temperatures, b) this correlation occurs at night, and c) this relationship depends on both the urban characteristics and the spatial resolution of the satellite product used as LST data source. Thus, the LST seems to be more representative as the pixel size is larger, from the $90 \mathrm{~m}$ to the $400 \mathrm{~m}$ and the $1 \mathrm{~km}$ pixel size in the case of ASTER. Specifically, a $\mathrm{R}^{2}$ fitting coefficient of $0.9381,0.9499$ and 0.9562 was obtained when comparing AST-08 at 90-m, 400-m and 1-km pixel size with air temperature at night respectively. A slightly worse fit was obtained between LST data from MODIS respect air temperature at ground level resulting in a $\mathrm{R}^{2}$ fitting coefficient of 0.8224 .

The direct relationship between LSTs obtained from ASTER and MODIS has also been proved, resulting in a $\mathrm{R}^{2}$ fitting coefficient of 0.9140 , having a greater influence the offset than the gain. This confirms that, although the LST calculation is done based on different algorithms (TES in the case of AST-08 and Split Window in the case of MOD11-L2) as well as using different number of bands and wavelengths ( 5 spectral bands in the case of AST-08 and 2 spectral bands in the case of MOD11L2), the LST data from both sensors are compatible. 
As for the absolute errors in temperature, if we derive air temperature from satellite LST, we can expect a mean absolute error of $1.58 \mathrm{~K}, 1.39 \mathrm{~K}$ and $1.34 \mathrm{~K}$ when using AST-08 at $90-\mathrm{m}$, $400-\mathrm{m}$ and $1-\mathrm{km}$ pixel size, respectively, and $2.16 \mathrm{~K}$ when using MOD11-L2.

Although it is possible that the higher differences between LST and air temperature are explained by the influence that humidity causes on temperature due to evaporation happened at water covers and the transpiration at vegetation covers, a more indepth study is proposed in order to identify the reliable reasons why maximum absolute errors of $10.96 \mathrm{~K}, 8.62 \mathrm{~K}, 6.17 \mathrm{~K}$ and $7.16 \mathrm{~K}$, were obtained in some specific locations.

Finally, this paper proves that nocturnal LST at satellite level might be an interesting product for studying UHI phenomenon. In fact, this first UHI map of the city of Strasbourg has served to prove the existence of a microclimatic thermal behaviour in the city as well as its morphology and spatial distribution. Specifically, a temperature variation of up to $6 \mathrm{~K}$ between the downtown and outskirts of Strasburg at a distance of only 7.5 $\mathrm{km}$ was shown.

Future studies will focus on an in-depth analysis of the influence that different urban and natural covers have on temperatures. In addition, the morphological and intensity variation of the UHI effect depending on the season of the year will be analysed taking the city of Strasbourg as a base.

\section{ACKNOWLEDGEMENTS}

Authors would like to thank Iberdrola S.L. and University of Salamanca for the funding in human resources provided through Cátedra Iberdrola VIII Centenary. We also express our gratitude to Marion Granjon, a student of Survey Engineering at INSA, which has collaborated in the development of this work. We also thank the Eurometropole Strasbourg for providing helpful data over Strasbourg.

\section{REFERENCES}

Aboulnaga, M. M., Elwan, A. F., Elsharouny, M. R., 2019. Climate Change Impacts on Urban Areas and Infrastructure. In Urban Climate Change Adaptation in Developing Countries (pp. 49-75). Springer, Cham.

Arriagada, N. B., Bowman, D. M., Palmer, A. J., Johnston, F. H., 2020. Climate Change, Wildfires, Heatwaves and Health Impacts in Australia. In Extreme Weather Events and Human Health (pp. 99-116). Springer, Cham.

Du, H., Wang, D., Wang, Y., Zhao, X., Qin, F., Jiang, H., Cai, Y., 2016. Influences of Land Cover Types, Meteorological Conditions, Anthropogenic Heat and Urban Area on Surface Urban Heat Island in the Yangtze River Delta Urban Agglomeration. Science of the Total Environment, 571, 461470 .

Gillespie, A., Rokugawa, S., Matsunaga, T., Cothern, J. S., Hook, S., Kahle, A. B., 1998. A Temperature and Emissivity Separation Algorithm for Advanced Spaceborne Thermal Emission and Reflection Radiometer (ASTER) images. IEEE Transactions on Geoscience and Remote Sensing, 36(4), 11131126.

Howard, L., 1833. The Climate of London, vol. 1. London: Harvey and Darton.

Keyimu, M., Wei, J., Zhang, Y., Ma, K., Fu., 2020. Climate Signal Shift Under the Influence of Prevailing Climate
Warming - Evidence from Quercus Liaotungensis on Dongling Mountain, Beijing, China. Dedrochronologia, 60, 125683.

Martilli, A., Krayenhoff, E. S., Nazarian, N., 2020. Is the Urban Heat Island Intensity Relevant for Heat Mitigation Studies?. Urban Climate, 31, 100541.

Merschroth, S., Miatto, A., Weyand, S., Tanikawa, H., Schebek, L., 2020. Lost Material Stock in Buildings due to Sea Level Rise from Global Warming: The Case of Fiji Islands. Sustainability, 12(3), 834.

Najjar, G., Colin, J., Kastendeuch, P., Ngao, J., Saudreau, M., Landes, T., Ameglio, T., Luhahe, R., Guillemin, S., Schreiner, G., 2015. A Three Years Long Fieldwork Experiment to Monitor the Role of Vegetation on the Urban Climate of the City of Strasbourg, France. International Conference On Urban Climate, 12th Symposium, Toulouse, France 20-24 July.

Oke, T. R., 1982. The Energetic Basis of the Urban Heat Island. Quarterly Journal of the Royal Meteorological Society, 108(455), 1-24.

Paranunzio, R., Ceola, S., Laio, F., Montanari, A., 2019. Evaluating the Effects of Urbanization Evolution on Air Temperature Trends Using Nightlight Satellite Data. Atmosphere, 10(3), 117.

Pereira, M. G., Parente, J., Amraoui, M., Oliveira, A., Fernandes, P. M., 2020. The Role of Weather and Climate Conditions on Extreme Wildfires. In Extreme Wildfire Events and Disasters (pp. 55-72). Elsevier.

Wan, Z., Dozier, J., 1996. A Generalized Split-Window Algorithm for Retrieving Land-Surface Temperature from Space. IEEE Transactions on Geoscience and Remote Sensing, 34(4), 892-905.

Sánchez-Aparicio, M., Andrés-Anaya, P., Del Pozo, S., Lagüela, S., 2020. Retrieving Land Surface Temperature from Satellite Imagery with a Novel Combined Strategy. Remote Sensing, 12(2), 277.

Revised January 2020 